IRA-International Journal of Technology \& Engineering

ISSN 2455-4480; Vol.08, Issue 02 (August 2017)

Pg. no. 5-14

Institute of Research Advances

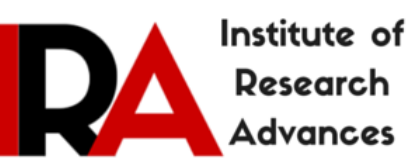

https://research-advances.org/index.php/IRAJTE

\title{
Hyper-spectral Remote Sensing of Water Quality Parameters in Lakes: A Case Study of Hyderabad City, Telangana State, India
}

\author{
V. Hema Sailaja ${ }^{1}$, P. Suman Babu ${ }^{2} \&$ M. Anji Reddy ${ }^{3}$ \\ ${ }^{1}$ Centre for Environment, Institute of Science and Technology, Jawaharlal Nehru Technological University \\ Hyderabad, Hyderabad-500085, Telangana, India. \\ ${ }^{2}$ Department of Civil Engineering, Anurag Group of Institutes, Gatkesar, R.R. Dist., Telangana- 501301, \\ India. \\ ${ }^{3}$ Centre for Environment, Institute of Science and Technology and Director R \& D, Jawaharlal Nehru \\ Technological University Hyderabad, Hyderabad -500085, Telangana, India.
}

Type of Review: Peer Reviewed.

DOI: http://dx.doi.org/10.21013/jte.v8.n2.p1

How to cite this paper:

Sailaja, VH., Babu, PS., Reddy, MA. (2017). Hyper-spectral Remote Sensing of Water Quality Parameters in Lakes: A Case Study of Hyderabad City, Telangana State, India. IRA International Journal of Technology \& Engineering (ISSN 2455-4480), 8(2), 5-14. doi:http://dx.doi.org/10.21013/jte.v8.n2.p1

(C) Institute of Research Advances.

\section{(cc) BY-NO}

This work is licensed under a Creative Commons Attribution-Non Commercial 4.0 International License subject to proper citation to the publication source of the work.

Disclaimer: The scholarly papers as reviewed and published by the Institute of Research Advances (IRA) are the views and opinions of their respective authors and are not the views or opinions of the IRA. The IRA disclaims of any harm or loss caused due to the published content to any party.

Institute of Research Advances is an institutional publisher member of Publishers Inter Linking Association Inc. (PILA-CrossRef), USA. The institute is an institutional signatory to the Budapest Open Access Initiative, Hungary advocating the open access of scientific and scholarly knowledge. The Institute is a registered content provider under Open Access Initiative Protocol for Metadata Harvesting (OAI-PMH).

The journal is indexed \& included in WorldCat Discovery Service (USA), CrossRef Metadata Search (USA), WorldCat (USA), OCLC (USA), Open J-Gate (India), EZB (Germany) Scilit (Switzerland), Airiti (China), Bielefeld Academic Search Engine (BASE) of Bielefeld University, Germany, PKP Index of Simon Fraser University, Canada. 


\begin{abstract}
This paper is a research work intended to present a comprehensive water quality modeling for predicting three water quality parameters (Chlorophyll (a), Turbidity and Secchi Depth) in typical Inland lake environments (Hussain sagar and Umda sagar) using Hyperspectral Remote sensing technique. They are estimated through regression models by combining the field Spectro-radiometer reflectance values with concurrent in situ ground data (Analytical) collected in the study area and correlated and validated with the available Hyperspectral data (Hyperion). A total of 180 in situ water sample and 900 spectral signatures were analysed during campaigns from 2010 to 2014 study period. The mean values of Chlorophylla varied between $6.983 \mathrm{mgL}^{-1}$ and $24.858 \mathrm{mgL}^{-1}$, Turbidity varied between $16.583 \mathrm{mgL}^{-1}$ and $48.867 \mathrm{mgL}^{-1}$ and Secchi depth varied between $0.104 \mathrm{mgL}^{-1}$ and $0.375 \mathrm{mgL}^{-1}$ over the study period considering the two lakes during pre and post monsoon seasons. The band ratios of the reflected spectra at R670/R710, R710/R740 and R710/R550 are used for the development of the mathematical model of chlorophyll-a, Turbidity and Secchi depth respectively. The trained sets of the pixels extracted from the hyperspectral data for pure spectra are processed for preparing the water quality distribution maps. When subjected to multivariant statistical tests of significance, the models have yielded satisfactory $R^{2}$ values. The model versus in situ analysis results demonstrated $R^{2}=0.81 \%$ for Chlorophyll-a, $R^{2}=0.81 \%$ for Turbidity and $R^{2}=0.78 \%$ for Secchi depth correlation and that of model versus satellite data exhibited $R^{2}=0.60 \%$ for Chlorophyll-a, $R^{2}=0.66 \%$ for Turbidity and $R^{2}=0.65 \%$ for Secchi depth mean efficiency.
\end{abstract}

Keywords: Water quality modeling, Lake Environments, Hyper-spectral Remote sensing, Regression, Band Ratio Model.

\title{
Introduction
}

With the onset of rapid urbanization and industrialization in recent decades the water bodies are left as hub for pollutants by the discharges of wastes untreated leaving the resource as scare commodity. This situation raises the essentiality and importance of water quality measurement, regular monitoring and proper management for reinstatement of the inland water bodies, thereby safeguarding the resource dependent inhabitants from adverse effects and protects the environment. Monitoring this varied mankind contributions towards disastrous and unsustainable conditions of the resources is a great challenge. Diversified pollutant concentrations exhibiting differential behaviours lead to significant alterations of the natural circumstances, which in turn is resulting in deleterious effects back onto the human society. Scrutinizing, preserving and improvising the lake water quality are crucial in conserving and protecting the environment. [1,2]. Remote sensing is the proven technology which can be visualized spatially and temporally and related methods can be used in establishing various water quality parameters was widely studied. [3-8]. Remote sensing has the ability to comprehend the changes in the past, estimate present impacts and gauge the future for effectual planning. Research has been done using Landsat MSS data to estimate water quality parameters by Landgrebe, [9] and Dekker et al. [10]. The multi spectral sensors served promisingly and helped in establishing many effective methods of spatial and spectral analysis.

After the launch of hyperspectral remote sensing attention was shifted to this technique due to its high spectral capability of identification and feature extraction. Hyperspectral remote sensing provides very narrow contiguous bands counting to hundreds with spectral resolution of $10 \mathrm{~nm}$ or less that would give a continuous spectral signature for more detailed interpretation. Besides, hyperspectral technique having the potentiality in water quality studies with huge future scope. The technique is being extensively used in coastal and marine water applications. [11]. In inland surface waters the spatial resolution should be high for the estimation of quality constituents but is limited by high spectral resolution of the hyperspectral imagery. Thus, Lake water quality monitoring can be improved by the usage of field spectro-radiometer along with using satellite imagery $[12,13,3]$ or the water quality can directly be derived from spectro-radiometer signatures from the field [14] overcoming the tedious conventional procedures. The large number of contiguous spectral bands of the hyperspectral imagery provides more prominent and accurate modeling of water quality parameters like Chl-a, TSS, SD, Turbidity etc., by Dekker et al. [15].

The paper presents characterization of water quality parameters viz., Chlorophyll-a, Turbidity and Secchi depth using spectral reflectance's from two lake waters of Hyderabad namely, Hussain sagar and Umda sagar. 
Hyperion data is used in the regression models development and the handheld spectroradiometer is used for ground truth measurements.

\section{Study area}

The Study areas are the lakes in the Hyderabad metropolitan namely, Hussain sagar and Umda Sagar. Fig: 1.1 reveals the location of the lakes chosen for the study and Table: 1.1 shows details of the Lakes selected for the study.

\section{Methodology}

The methodology of the present study has been framed in such a way that the research objective of the study is met in a structural manner which has been carried out in a systematic investigation that is delineated in a schematic diagram as presented in Fig: 1.2.

The Hyperion is a high resolution hyperspectral imaging instrument (HSI) which is capable of providing high resolution data set in hundreds of spectral bands. The Hyperion images the earth's surface in 220 contiguous spectral bands from 0.4 to $2.5 \mu \mathrm{m}$ with high radiometric accuracy, at a ground resolution of $30 \mathrm{~m}$. Through this large number of spectral bands, complex land eco-systems can be imaged and accurately classified with enhanced predictions. The swath width of the sensor is $7.75 \mathrm{~km}$, spectral band width is $10 \mathrm{~nm} \& \mathrm{SNR}$ is $161(550 \mathrm{~nm}), 147(700 \mathrm{~nm}), 110(1125 \mathrm{~nm})$, and $40(2125 \mathrm{~nm})$. The radiometric survey is done through the ASD field-handheld spectroradiometer with the wavelength range of $325-1075 \mathrm{~nm}$. The spectral resolution is $3 \mathrm{~m}$ at $700 \mathrm{~nm}$ with sample interval of $1.6 \mathrm{~nm}$. This field Spec® Hand-Held Spectro radiometer well suitable for applications. in precision measurement. The locations and coordinates of the sampling points in the study areas (lakes) is represented in Fig: 1.3.

Frequency of Samples collected from the study areas is twice an year, which is pre-monsoon in the month of April and post-monsoon in the month of October for the study period of 2010, 2011 and 2012 and for the study period of 2013 and 2014 the sampling was done in the month of May and October. Number of Samples collected from the study areas during every period of study is 12 water samples \& 60 spectra from Hussain sagar and six water samples \& 30 spectra from Umda sagar lake.

\section{Research Findings}

The mathematical model was developed based on the band ratios since the fundamental principle behind the band ratios is that the representatives of absorption/scattering features are the selected two spectral bands. [16]. The band rationing technique and regression based analysis have been used to develop the model by dividing the central narrow absorption bands of the quality parameter. Water quality parameter is accurately quantified by the Band ratio model. The ratio of the reflected values at R670/R710, R710/R740 and R710/R550 were found to be optimum for the estimation of water quality parameters, chlorophyll-a, Turbidity and Secchi depth respectively. Based on the band ratio results of estimation of water quality parameters by using hyperspectral band ratio model has given good correlation and lead to the development of the model for subsurface water reflectance and validated with in situ analysis data. Much research by various researchers like Dekker [10] and [17-19] has evolved Empherical regression formulas for lake water quality prediction using the spectroradiometer field data based ratios. The final concentrations output from the model is utilised in preparing spatial distribution of the optical parameter under study emphasizing the water quality estimated in the selected lakes.

The spectral data were collected from $0.5 \mathrm{~m}$ above the water surface. The spectroradiometer with $325 \mathrm{~nm}$ to $1075 \mathrm{~nm}$ wavelength range is used to collect the data in the range of $350-950 \mathrm{~nm}$. The sampling interval of $5 \mathrm{sec}$ with a radiometric field is of $25^{\circ}$. The collected spectra are processed and the water spectra of the lakes are presented in Fig: 1.4 .

From the Fig: 1.4 it is observed that the reflected spectra have absorption and reflectance at various wavelengths like R550, R670, R710, R740. Further these values were used for the development of the mathematical model to calculate the concentration of the water quality parameters viz., Turbidity, SD and Chl-a.

\section{Turbidity}

Turbidity defines the clarity of the water bodies which determines the quality of the waters. Turbidity is considered to be the proxy of suspended inorganic matter and phytoplankton scattering. [20,21]. The ratio of R710/R740 is the NIR region where turbidity is identified to reflect with high peaks. The model developed for the estimation of turbidity in the lake waters is as follows:

Turbidity $(\mathrm{NTU})=\mathrm{m}(\mathrm{R} 710 / \mathrm{R} 740) 2-\mathrm{n}(\mathrm{R} 710 / \mathrm{R} 740)+1$ 
In Fig: 1.5 the Regression for Measured versus Estimated values of Turbidity in the two lakes under Investigation is shown.

\section{Chlorophyll-a}

The water quality parameter chlorophyll- a indicates the presence of large quantity of phytoplankton in the water bodies. For chlorophyll-a pigment distinct absorption is strong at $670 \mathrm{~nm}$ (red region) and maximum reflectance is at 710nm (NIR region). R670/R710 is the reflectance ratio of the parameter chlorophyll-a which is applied to the model. The model developed for chlorophyll-a in the lakes standing suitable is as follows:

Chl-a $(\mu \mathrm{g} / \mathrm{l})=\mathrm{m}(\mathrm{R} 710 / \mathrm{R} 670)^{2}-\mathrm{n}(\mathrm{R} 710 / \mathrm{R} 670)+1$

In Fig: 1.6 the Regression for Measured versus Estimated values of Chlorophyll-a concentration in the two lakes under investigation is shown.

\section{Secchi Depth}

Secchi depth denotes the optical transparency of the water in the lakes defining the light penetration level. The red and green bands R710 and R550 found to have the information regarding the secchi depth. This ratio based model developed gave better results for the determination of the transparency depth in meters. The model is stated as follows:

Secchi Depth $(m)=m(R 710 / R 550)+n$

In Fig: 1.7 the Linear Regression for Measured versus Estimated values of Secchi Depth in the two lakes under investigation is shown.

Fig 1.8 to 1.10 the regression graphs exhibit the correlation between the developed mathematical model and the satellite image based spectral results of each parameter in all the four lakes. Turbidity, and Chl-a displayed second order polynomial regression as the best fit and the secchi depth showed linear regression as the best fit validating the developed models. The comparative best fit between linear and polynomial regression is evident from the graphs.

The use of the statistical regression analysis in the parameter determinations helped for the validation of the model results and attain scientific approach. Regression analysis worked well in all the parameters and the two lakes in the study area. The developed monitoring hyperspectral technique is considered effective in turbid waters.

\section{Comparative analysis}

The water quality parameters have been estimated through chemical analysis measurement method, model based in situ data estimation and model based satellite data estimation. The empirical relationship between the chemical analysis \& model and satellite analysis \& model are presented in the Table: 1.2.

After evaluating the different band ratios for different parameters the best results were obtained with $0.80 \%$ accuracy from the model developed with respect to in situ analysis and $0.64 \%$ with respect to the satellite data result.

Another important finding is the understanding of the spectral behaviour of the water constituents, specific absorption bands for the parameters concentrations. The outcome of the investigations leads to the evaluation of the linear mixing model while estimating the abundance of the parameters from the mixed hyperspectral signatures of the satellite data set. The study helped to identify the parameters from the reflectance peaks in the spectral data sets from the field and verified with the Hyperion data set and correlated with the in situ analysis data.

\section{Spatial distribution maps}

The regression analysis performed on all the parameters on all the lakes gave appreciable R2 values to be the best estimators. The model results are used to prepare the spatial distribution maps for the quality parameters of the two lakes under investigation of this study which present the pictorial visualization of the water quality which would be very useful in the monitoring and planning of the lakes and their management. The spatial distribution of the three water quality parameters, Turbidity, Secchi depth and Chlorophyll-a for the two lakes, Hussain sagar in Fig: 1.11 and Umda sagar in Fig 1.12 through premonsoon 2010 to post monsoon season 2014 respectively are presented. 


\section{Conclusion and Recommendations}

The Hyper-spectral data application in the estimation of water quality parameters allow to differentiate and understand the water constituents and the light interactions with water and to develop predictive models as tools to monitor the seasonal variability of the parameter concentrations in the lake waters. Hyperspectral remote sensing therefore allows accurate and potential usability in classification of the lakes projecting the pollution status. Due to its wide range of spectral bands the study of the quality constituents has a huge scope of prediction which is not supportive in the multispectral remote sensing. Although, the assessment is complex involving factors of great accountability in considerations the results are appreciable and helpful. Utmost care is required during the data collection keeping significant atmospheric conditions in view and the data processing procedures to bring down the errors. It is found that the reflectance peaks in NIR domain is well correlated with turbidity, the ratio of green and NIR domain are best for concentrations of secchi depth predicted and that of red domain has proven most appropriate for estimating chlorophyll-a concentrations. The developed mathematical models can be successfully applied for monitoring the water quality of the lakes.

Future research scope is to assess the water pollutants such as: volatile organic chemicals, heavy metals, and contaminants of bacterial origin where few studies have been conducted can be monitored using hyperspectral remote sensing.

\section{Nomenclature:}

NIR- Near Infra Red

NTU-Nephelometric turbidity units

$\mathrm{R}^{2}$ - Regression

\section{References}

[1] Ritchie, J. C, Schiebe, F. R, Cooper, C, \& Harrington, J. A. Jr., (1994). Chlorophyll measurements in the presence of suspended sediment using broad band spectral sensors aboard satellites, Journal of Freshwater Ecology 9, 197-206.

[2] Nellis, M. D, \& Harrington, J. A. Jr. \& Wu, J.,( 1998). Remote sensing of temporal and spatial variations in pool size, suspended sediment, turbidity, and Secchi depth in Tuttle Creek Reservoir, Kansas: 1993, Geomorphology Papers, , 21, 281-293.

[3] Ostlund C., Flink, P. Strombeck, N., Pierson, D. Lindell, T.,( 2001). Mapping of the water quality of Lake Erken, Sweden, from Imaging Spectrometry and Landsat Thematic Mapper, The Science of the Total Environment, 268, pp.139-154.

[4] Koponen, S.; Pulliainen, J.; Kallio, K.; Hallikainen, M., (2002). Lake water quality classification with airborne hyperspectral spectrometer and simulated MERIS data, Remote Sens. Environ. 79, 51-59.

[5] Vignolo, A.; Pochettino, A.; Cicerone, D.,( 2006). Water quality assessment using remote sensing techniques: Medrano Creek, Argentina, J. Environ. Manage., 81 (4), 429-433 (5 pages).

[6] Wang, F., Han, L., Kung, T., and Van Arsdale, R.B.,(2006). Applications of Landsat-5 TM imagery in assessing and mapping water quality in Reelfoot Lake, Tennessee. Int. J. Remote Sens., 27, pp. 5269-5283.

[7] Alparslan, E., Aydöner, C., Tufekci, V., and Tüfekci, H. (2007) . Water quality assessment at Ömerli Dam using remote sensing techniques. Environ. Monit. Assess., 135, 391-398.

[8] Mancino, G.; Nolè, A.; Urbano, V.; Amato, M.; Ferrara, A.,(2009). Assessing water quality by remote sensing in small lakes: The case study of monticchio lakes in southern Italy, iFor. Biogeosci. For. 2, 154-161.

[9] Landgrebe D., (1999). Some fundamentals and methods for hyperspectral image data analysis, Systems and Technologies for Clinical Diagnostics and Drug Discovery II, 3603. 6 pp.

[10] Dekker, A.G. and Peters, S.W.M.,(1993). The use of the Thematic Mapper for the analysis of eutrophic lakes: a case study in the Netherlands, International Journal of Remote Sensing, Vol. 14, 799-821.

[11] Santini, F.; Alberotanza, L.; Cavalli, R.M.; Pignatti, S. , (2010). A two-step optimization procedure for assessing water constituent concentrations by hyperspectral remote sensing techniques: An application to the highly turbid Venice lagoon waters, Remote Sens. Environ. 114, 887-898.

[12] Giardino, C., M. Pepe, P. A. Brivio, P. Ghezzi, and E. Zilioli, (2001). Detecting chlorophyll, Secchi disk depth, and surface temperature in a sub-alpine lake using Landsat imagery, The Science of the Total Environment 268 (1-3): 1929.

[13] George, D. G. and T. J. Malthus, (2001). Using a compact airborne spectrographic imager to phytoplankton biomass in a series of lakes in north Wales, The Science of the Total Environment 268 (1-3): 215-226.

[14] Gons, H. J., (1999). Optical teledetection of chlorophyll-a in turbid inland waters, Environmental Science and Technology 33 (7): 1127-1132.

[15] Dekker, A. G., T. J. Malthus, M. M. Wijnen, and E. Seyhan, (1992). The effect of spectral bandwidth and positioning on the spectral signature analysis of inland waters, Remote Sensing of the Environment 41: 211-225.

[16] Gin, K.Y.et al., (2002). Application of spectral signatures and colour ratios to estimate chlorophyll in Singapore's coastal waters, Estuarine, Coastal and Shelf Science, 55, pp. 719-728.

[17] Gitelson, A., (1993). Algorithms for remote sensing of phytoplankton pigments in inland waters", Advances in Space Research, 13, pp. 197-201.

[18] Jupp, D.L., J.T.O. Kirk, and G.P. Harris., (1994a). Detection, identification and mapping of cyanobacteria using remote sensing to measure the optical quality of turbid inland waters, Australian Journal of Freshwater Research 45: 801-828. 
[19] Jupp, D.L., G. Byrne, E. McDonald, J. Anstee, G. Harris, and J. Smith, (1994b). Monitoring optical water quality of the Hawkesbury River using airborne remote sensing, CSIRO Division of Water Resources, Consultancy Report No. 94/9.

[20] Zimba P. V., Gitelson A. A., (2006). Remote estimation of chlorophyll concentration in hyper-eutrophic aquatic systems: model tuning and accuracy optimization, Aquaculture 256:272-286. doi:10.1016/j.aquaculture. 2006.02.038.

[21] Gitelson, A. A., Dall'Olmo, G., Moses, W., Rundquist, D. C., Barrow, T., Fisher, T. R., Holz, J., (2008). A simple semianalytical model for remote estimation of chlorophyll-a in turbid waters: Validation, Remote Sensing of Environment, $112(9), 3582-3593$.

\section{(TABLES AND FIGURES)}

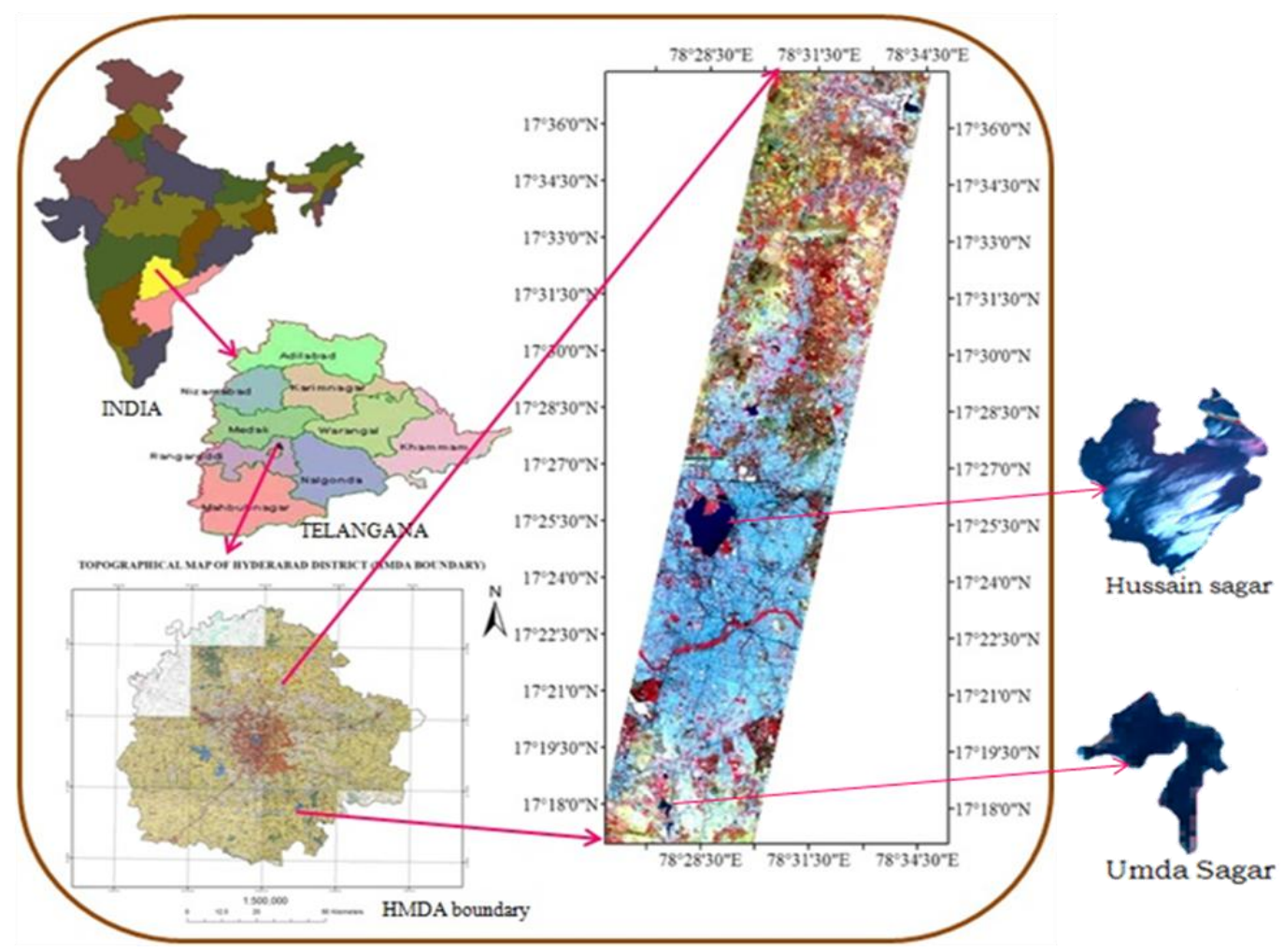

Fig: 1.1 Location map of the Study areas

Table: 1.1 showing Details of the Lakes selected for the study

\begin{tabular}{|l|l|l|l|}
\hline S.No. & Name of the Lakes & $\begin{array}{l}\text { Location } \\
\text { (Lat/Long) (Centre } \\
\text { point) }\end{array}$ & Area of the Lakes \\
\hline 1 & Hussain Sagar & $\begin{array}{l}78^{\circ} 28^{\prime} 26^{\prime \prime} \mathrm{E} \\
17^{\circ} 25^{\prime} 24^{\prime \prime} \mathrm{N}\end{array}$ & 461.41 hectares \\
\hline 2 & Umda sagar & $\begin{array}{l}78^{\circ} 27^{\prime} 25^{\prime \prime} \mathrm{E} \\
17^{\circ} 17^{\prime} 55^{\prime \prime} \mathrm{N}\end{array}$ & 35.83 hectares \\
\hline
\end{tabular}




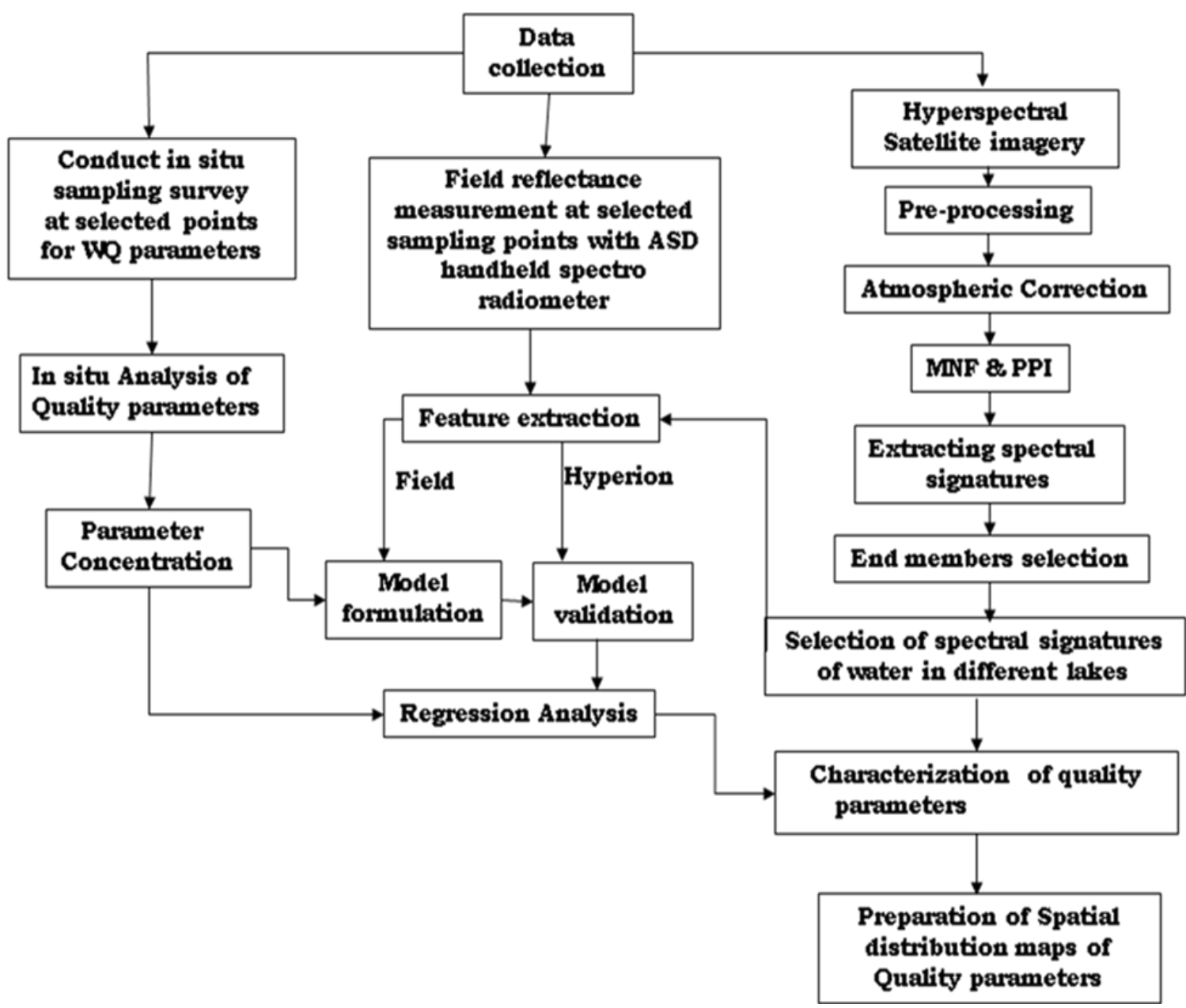

Fig:1.2 Methodology flow chart of the research work.

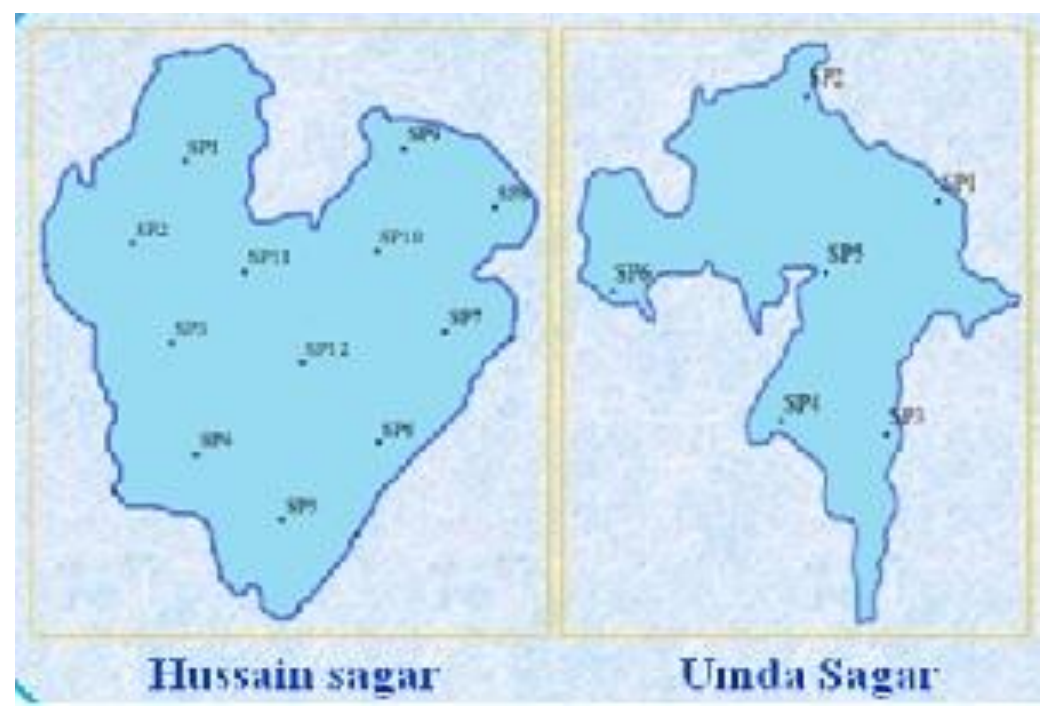

Fig: 1.3 Shows the sampling locations in each lake. 

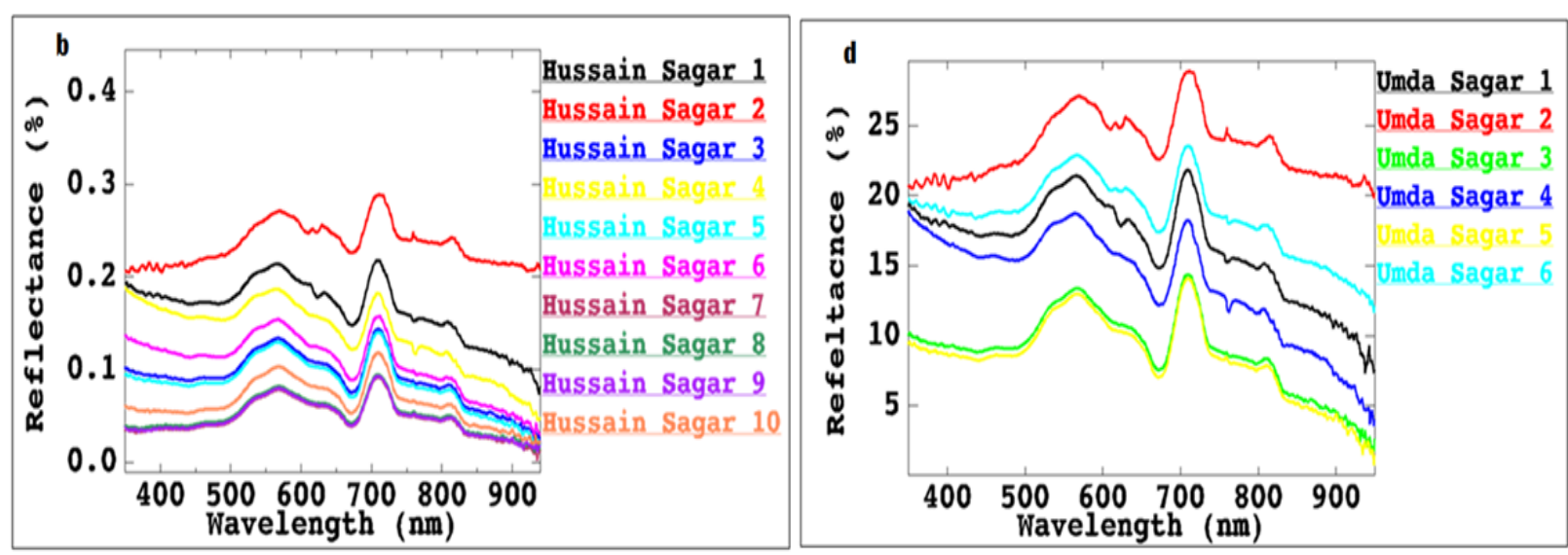

Fig: 1.4 Portrays the spectral signatures of different water quality parameters of the lakes under study (bHussain sagar and d- Umda sagar).
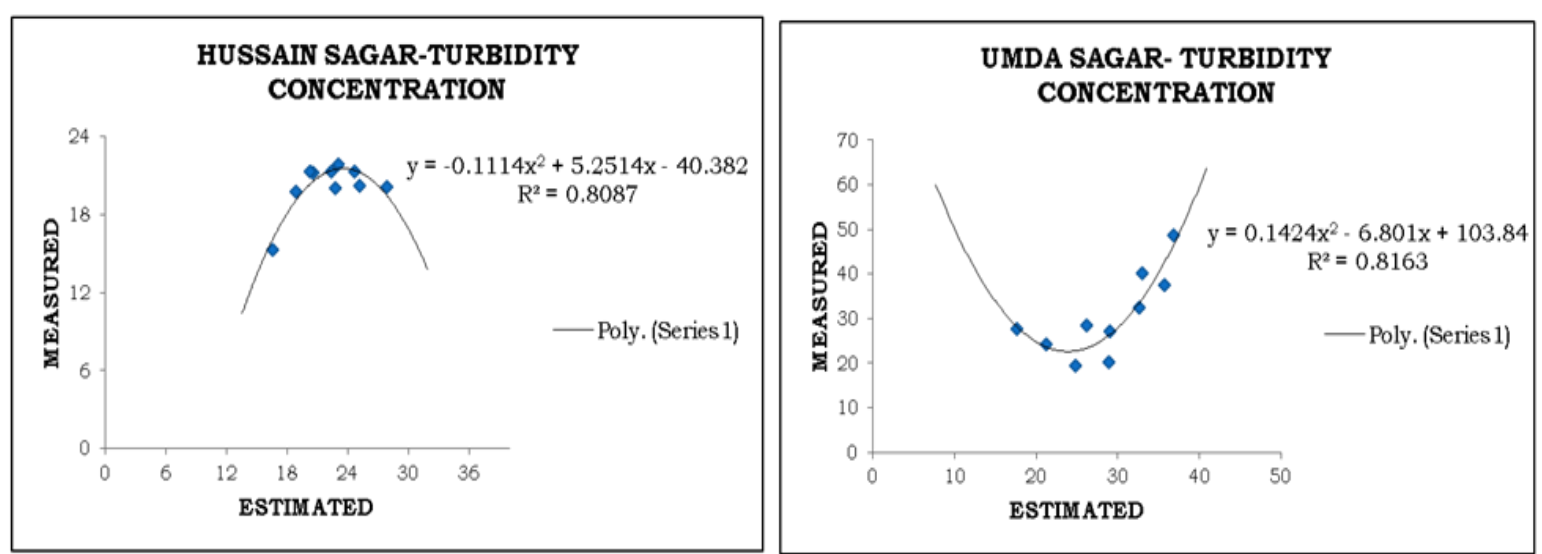

Fig: 1.5 Regression for Measured versus Estimated values of Turbidity in the two lakes under investigation.
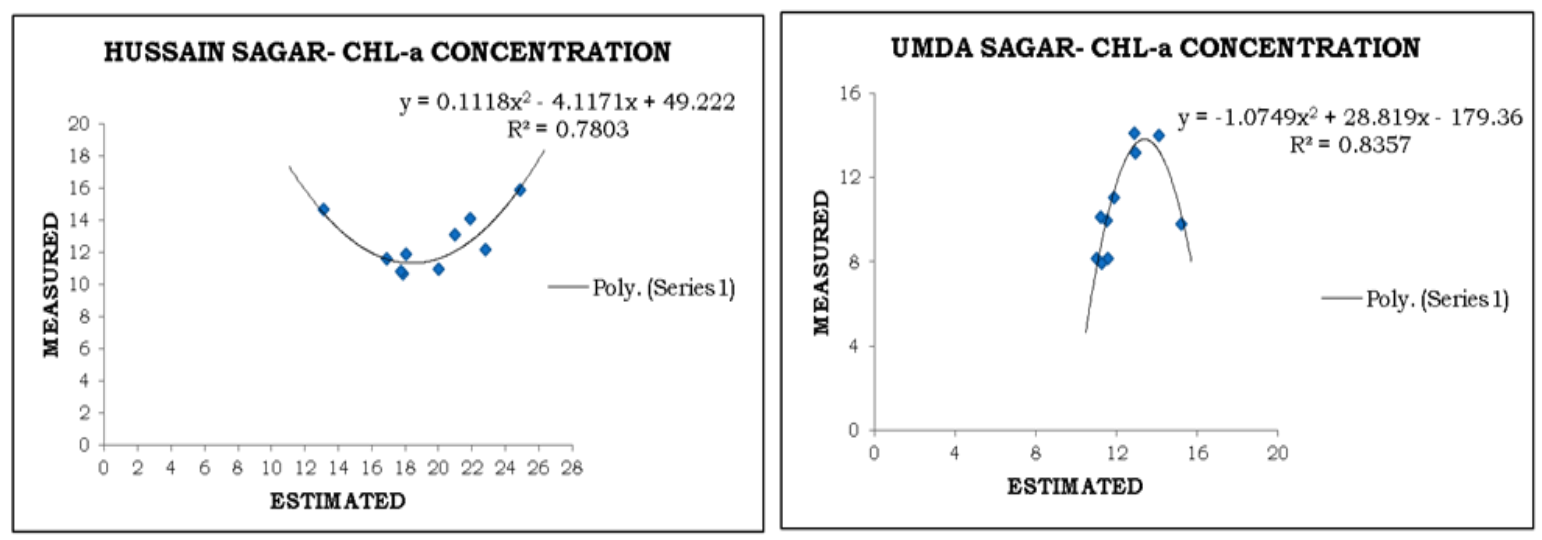

Fig: 1.6 Regression for Measured versus Estimated values of Chlorophyll-a concentration in the two lakes under investigation. 

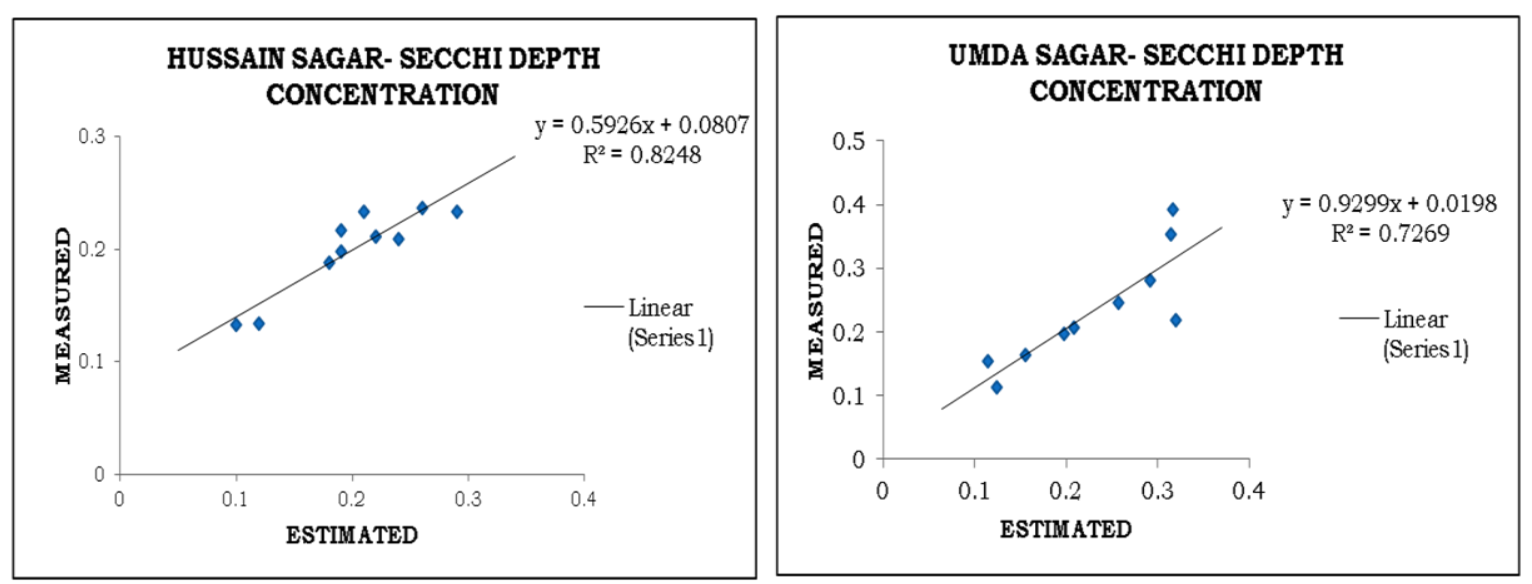

Fig: 1.7 Linear Regression for Measured versus Estimated values of Secchi Depth in the two lakes under investigation.
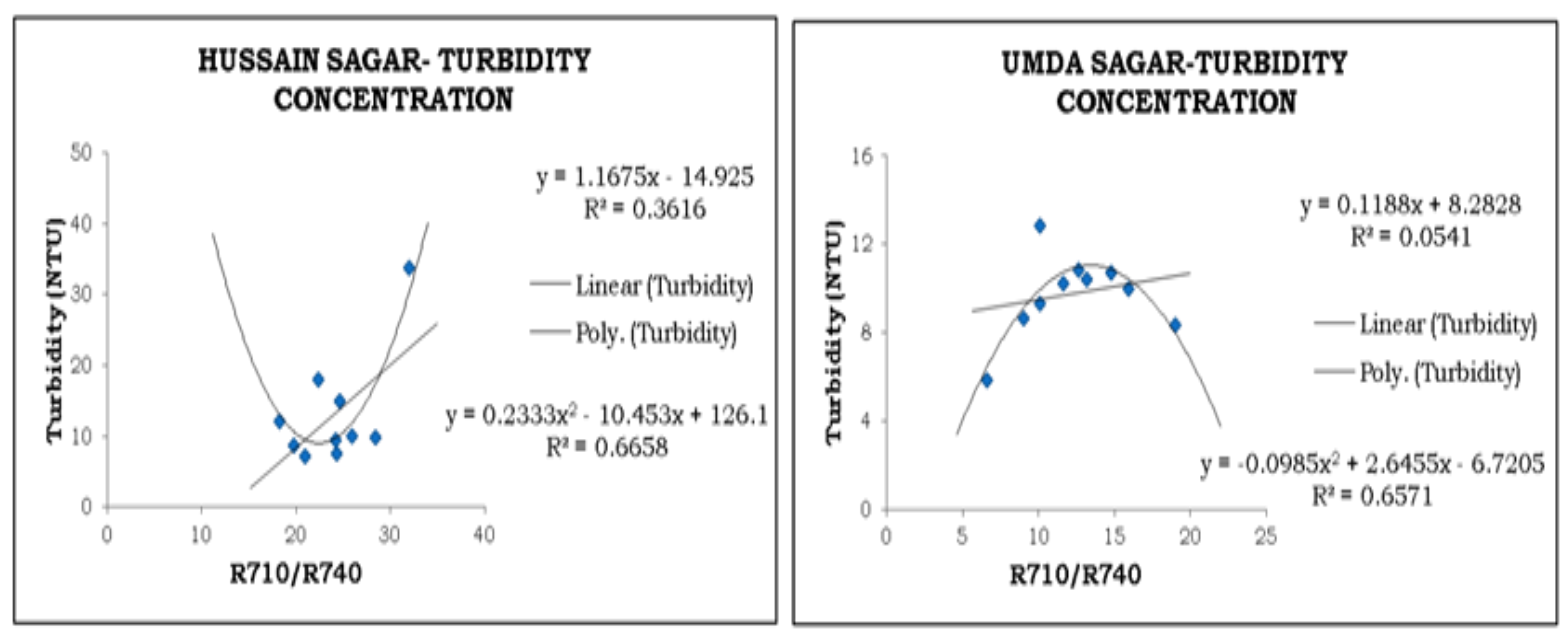

Fig: 1.8 Regression model for Estimating Turbidity
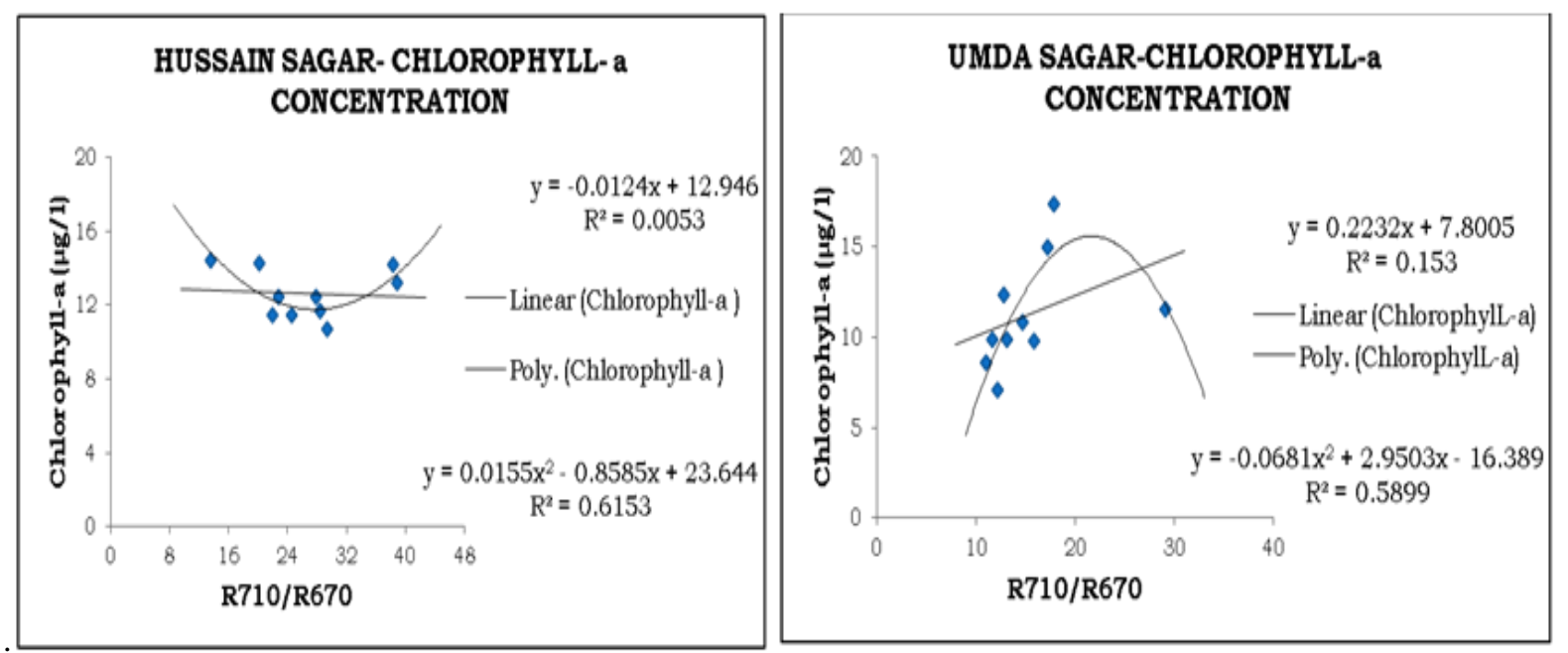

Fig: 1.9 Regression model for Estimating Chlorophyll-a. 

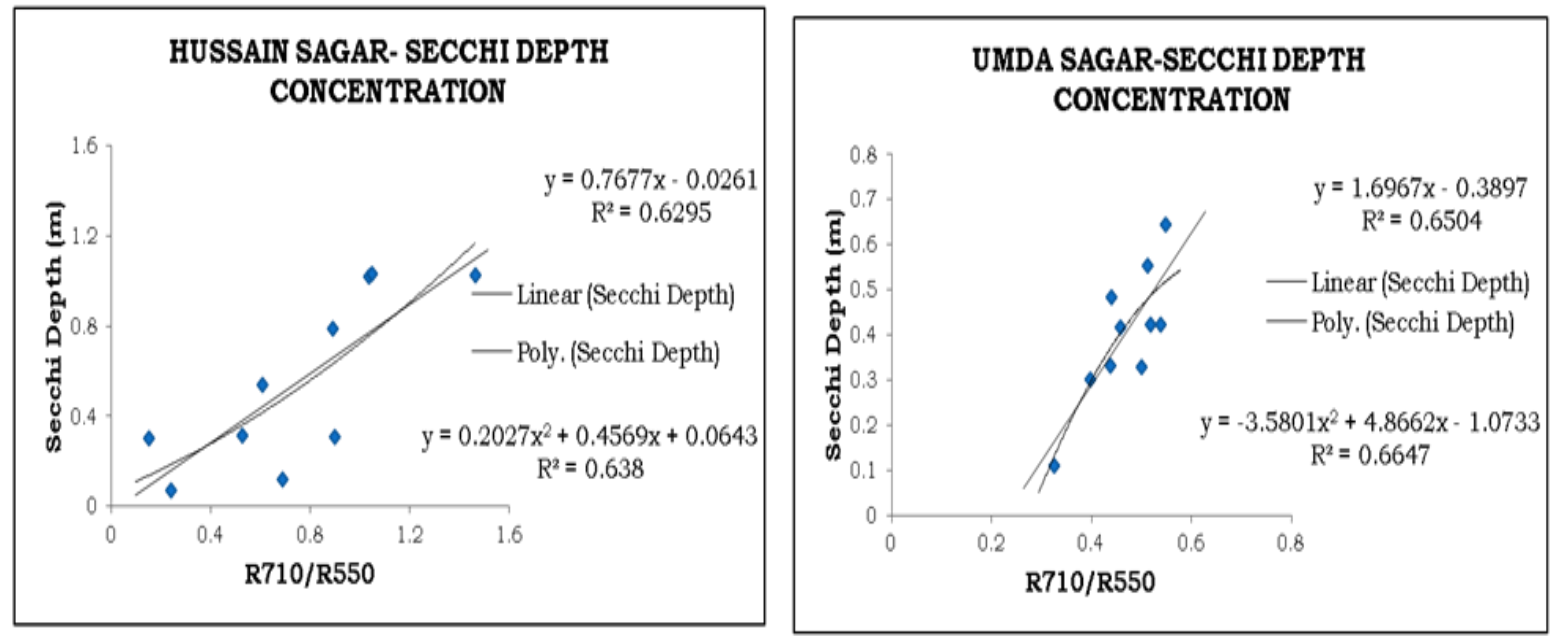

Fig: 1.10 Regression model for Estimating Secchi Depth.

Table 1.2 Comparison table between Model, In situ data and satellite data.

\begin{tabular}{|c|c|c|c|}
\hline S. No & Parameter & $\begin{array}{l}\mathbf{R}^{2} \\
\text { Model } \\
\text { Hyperion }\end{array}$ & $\begin{array}{l}\mathbf{R}^{2} \\
\text { Chemical Analysis vs. Model }\end{array}$ \\
\hline 1 & Turbidity & 0.66 & 0.81 \\
\hline 2 & Secchi Depth & 0.65 & 0.78 \\
\hline 3 & Chlorophyll-a & 0.60 & 0.81 \\
\hline & Average & 0.64 & 0.80 \\
\hline
\end{tabular}

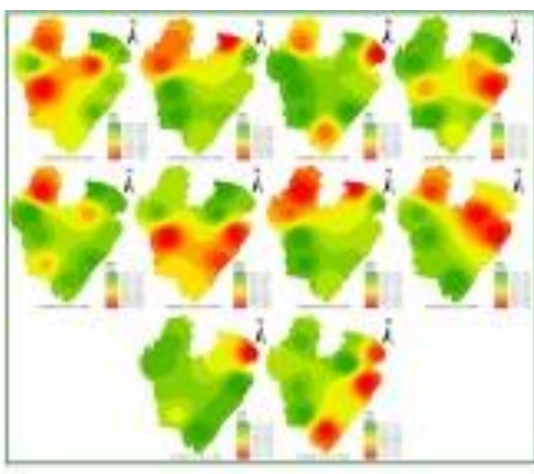

Turbidity

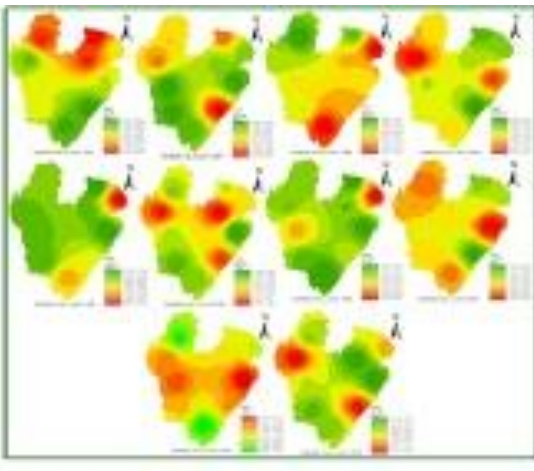

Chlorophyll-a

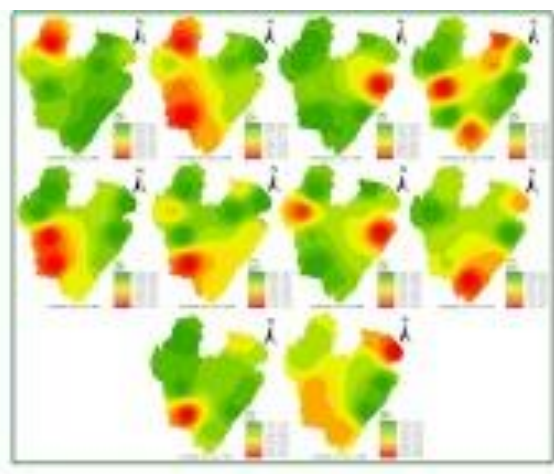

Secchi depth

Fig: 1.11 Turbidity, Secchi depth and Chlorophyll-a Concentrations in Hussain Sagar during pre and post monsoon seasons of the study period 2010 to 2014 .

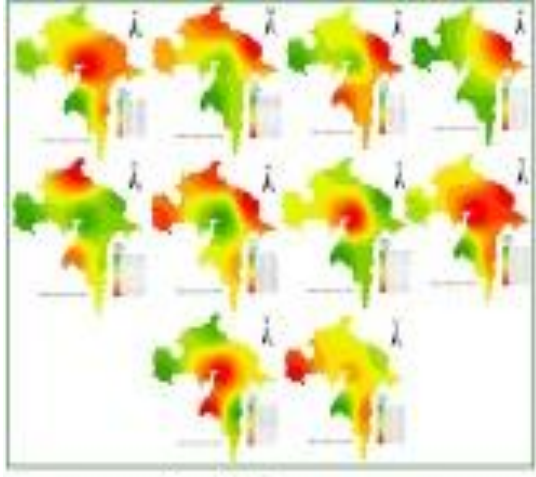

Tubidity

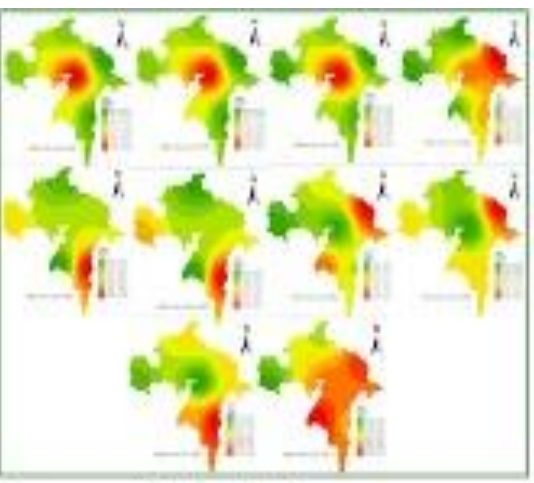

Chlorophyll-a

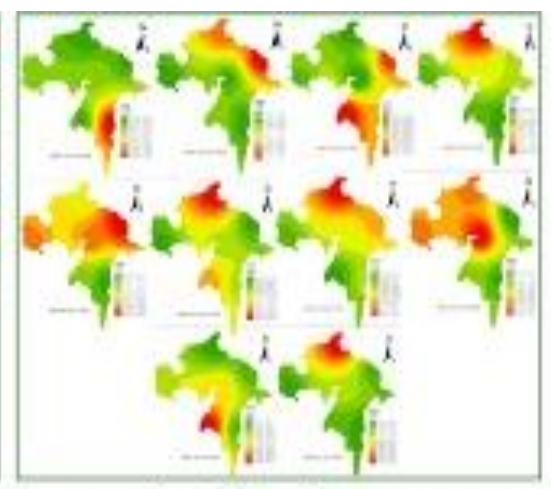

Secchi depth

Fig: 1.12 Turbidity, Secchi depth and Chlorophyll-a Concentrations in Umda Sagar during pre and post monsoon seasons of the study period 2010 to 2014 . 